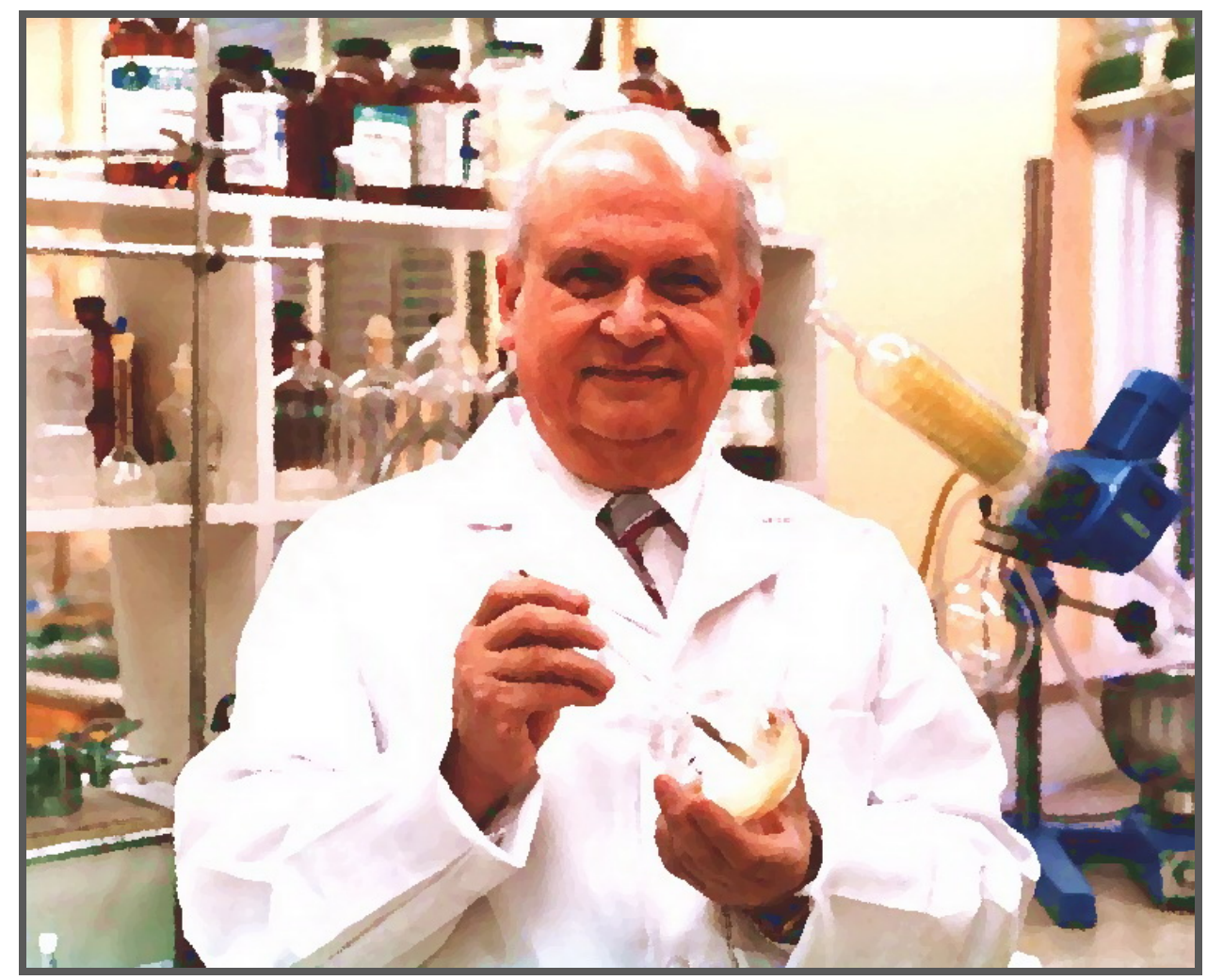

\section{RONALD G. MICETICH \\ (1931-2006): \\ A Scientific Career}

Ronald Micetich was born in Podanur, Coimbatore (South India). Following receipt of B.Sc. Honors (Chemistry, Loyola College, Madras) and M.A. (Chemistry, Madras University) degrees in India, Ron obtained a Ph.D. (Organic Chemistry, University of Saskatchewan, Canada) in 1962. Ron initiated his interest in microbiology while he was a postdoctoral fellow at the National Research Council of Canada. During the period 1963-1980, Ron held a number of industrial appointments where he rapidly advanced his industrial scientific career (research scientist $\rightarrow$ associate research director $\rightarrow$ acting research director $\rightarrow$ director pharmaceutical / agricultural research) at Raylo Chemicals in Edmonton, Alberta. In 1981 Ron joined the Faculty of Pharmacy \& Pharmaceutical Sciences at the University of Alberta as an Adjunct
Professor at which time a highly successful drug development program was established with Taiho Pharmaceuticals. This joint industrial collaboration led to the birth of SynPhar with Dr. Micetich as Chairman of the Board, President, CEO and Research Director (1987-1999). Ron, again as Chairman of the Board, CEO and Research Director, established NAEJA (North America, Europe, Japan, Asia) Pharmaceuticals in 1999 with a rollover of assets, including staff, equipment and intellectual property, from SynPhar Laboratories. What began as a full fledged pharmaceutical company with an extensive intellectual property portfolio and a proven track record evolved into an internationally respected pharmaceutical outsource service provider. NAEJA has carved a unique niche in the outsource industry offering extensive discovery experience and expertise. Today, NAEJA has over 120 staff that consists of over $90 \%$ scientists holding PhD degrees. 
Ron had a special admiration for the heteroatoms nitrogen, oxygen and sulfur. Heterocyclic ring systems and substituents containing these heteroatoms were hallmark features of his research. His research interests encompassed all aspects of the design, synthesis, biological evaluation, structure-activity relationships, and development of new pharmacologically active compounds (drugs) with special emphasis on infectious disease (antibiotics, antifungals, antivirals). The benchtopto-market research pioneered by Dr. Micetich culminated in the development of two drugs. These include the non-steroidal anti-inflammatory drug (NSAID) marketed as "Mofezolac" in Japan by Welfide Pharmaceuticals, and the $\beta$-lactamase inhibitor "Tazobactam" that is marketed worldwide by Wyeth (American Home Products) in combination with piperacillin as Zosyn ${ }^{\circledR}$ or Tazosyn ${ }^{\circledR}$.

Dr. Micetich's scientific achievements have been recognized by receipt of distinguished awards. In this regard, Ron was the recipient of the first-ever Alberta Science and Technology Leadership Award (ASTech) honoring innovation in Alberta Science and Technology (May, 1990), and an Immigration Achievement Award for Business Research \& Development (February, 1997). In 2007, Ron was honored posthumously by induction into the Alberta Bioindustry Hall of Fame that recognizes people who have demonstrated leadership in the industry and made extensive and tangible contributions to the Alberta and Canadian life sciences sector, industry development, public policy, ambassadorship, and education.

\section{Scientific Reviewers}

Prabhat Arya, Toronto, Canada

Dion Brocks, Edmonton, Canada

Thomas Chang, Vancouver, Canada

John Clements, Kenilworth, U.S.A.

Ferenc Fulöp, Eotvos, Hungary

Margaret Gray, Edmonton, Canada

Sherif Hanafy, Edmonton, Canada

Piet Herdeqijn, Leuven, Belgium

Xin-Min Li, Winnipeg, Canada

David Jakeman, Halifax, Canada
During his tenure as an Adjunct Professor in the Faculty of Pharmacy \& Pharmaceutical Sciences at the University of Alberta during the period 19811986 , Ron generously provided his valuable time to teaching in the undergraduate and graduate programs, and to the supervision of postdoctoral fellows. His thoughtful conception and foresight was responsible for establishing the 'Taiho' endowed fund that provides financial funding to support collaborative pharmaceutical or related research activities between scientists (staff, postdoctoral fellows, graduate students) from Japanese Universities and the U. of A. Ron was instrumental in arranging Exchange Agreements between the University of Alberta and Universities in Japan (Chiba, Toho, Meiji, Shizuoka, Hokkaido), Chung Aung University in South Korea, and Mahedol University in Thailand. The "Dr. Ronald Micetich Memorial Graduate Scholarship", endowed by NAEJA, his family, and friends, in the Faculty of Pharmacy \& Pharmaceutical Sciences serves to preserve his infectious smile and pleasant memories for all who knew him.

In conclusion, we would like to thank Fakhreddin Jamali, Editor of JPPS, for his support and encouragement that made this Micetich Memorial Issue possible. The production editing assistance of Rahim Bhatia was greatly appreciated. We are also thankful to all those individuals who provided reviews that maintained high manuscript standards, and to the authors who dedicated their research to the memory of a true friend.

Kamaljit Kaur, Edmonton, Canada

Lakshmi Kotra, Toronto, Canada

Glen Kwon, Madison, U.S.A.

Gordon McKay, Saskatoon, Canada

John Mercer, Edmonton, Canada

Adil Nazarali, Saskatoon, Canada

Keykavous Parang, Kingston, U.S.A.

Manfred Schneider, Wuppertal, Germany

Jashim Uddin, Nashville, U.S.A.

Alex Zakhartchouk, Saskatoon, Canada 